\title{
Blood coagulation parameters and von Willebrand factor activity in critical stage COVID-19 patients
}

\author{
Aliaxei V. Marochkov ${ }^{1}$, Dzmitry S. Tsopau ${ }^{2}$, Artur L. Lipnitski ${ }^{1}$, Alexander N. Osipenko ${ }^{3 *}$, \\ Valery V. Kanankou ${ }^{2}$, Iryna A. Kupreyeva ${ }^{1}$, Volha U. Dazortsava ${ }^{1}$ \\ ${ }^{1}$ Department of Anesthesiology and Intensive Care, Mogilev Regional Clinical Hospital, Mogilev, Belarus \\ ${ }^{2}$ Department of Anesthesiology and Intensive Care, Mogilev Hospital No. 1, Mogilev, Belarus \\ ${ }^{3}$ Central Educational and Research Laboratory, Mogilev State A. Kuleshov University, Mogilev, Belarus
}

\section{Introduction}

The main pathological syndrome of coronavirus disease 19 (COVID-19) is an severe acute respiratory syndrome coronavirus 2 (SARS-CoV-2). Recently, however, many researchers have drawn attention to a significant coagulation imbalance in COVID-19 patients, confirmed by laboratory findings [1-5] as well as postmortem data [6]. The number of studies on coagulopathy in COVID-19 patients with SARS-CoV-2 is limited. Also, there are currently no studies that would analyze von Willebrand factor (VWF) activity in these patients at critical stage. Consequently, the objective of this study was to determine the changes in coagulation parameters that are specific for COVID-19 patients.

\section{Materials and methods}

We analyzed the coagulation status in 16 confirmed COVID-19 patients who received treatment at the intensive care units (ICUs) at the Mogilev Hospital No.1 and Mogilev Regional Clinical Hospital, Republic of Belarus, in the period from March 1 to May 20, 2020. The CoVID-19 diagnosis was confirmed by reverse transcription-polymerase chain reaction (RT-PCR) and chest computed tomography (CT) scan where the specific manifestations (i.e. ground-glass opacity and consolidation) were observed. All patients were admitted to the ICU with moderate to severe respiratory distress syndrome in accordance with the Berlin definition and classification.

Of the 16 patients enrolled, six (37.5\%) were male and $10(62.5 \%)$ were female; the median (interquartile range) age was $59.0(51.5-70)$ years, the weight was
$91.0(78-108) \mathrm{kg}$, the height was $168.0(167-171) \mathrm{cm}$, and the body mass index was $31.2(27.1-37.9) \mathrm{kg} / \mathrm{m}^{2}$. 12 patients received respiratory support, and another four patients received high-flow oxygen therapy. Of the 16 patients enrolled, 10 (62.5\%) patients were transferred from the ICU for follow-up care, and six (37.5\%) patients died.

At the time of blood sampling for the study, all patients received anticoagulant therapy: eight patients received enoxaparin sodium 4,000 IU anti-Xa/day, two patients received sodium dalteparin 10,000 IU anti-Xa/day, four patients received sodium dalteparin 20,000 IU anti-Xa/day, and two patients received unfractionated heparin 20,000 units/day.

The coagulation status was determined once on the first day of ICU admission. Blood samples were collected using vacuum blood collection systems. To perform the study, an automatic haemostasis analyzer ACL 10000 (Instrumentation Laboratory, MA, USA) was used. The following assays were performed: activated partial thromboplastin time (APTT), prothrombin time (PT), international normalized ratio (INR), prothrombin complex activity (PCA), fibrinogen, plasminogen, antithrombin III, D-dimers, and vWF activity.

The data was presented as median and interquartile range (median $\left(25^{\text {th }}-75^{\text {th }}\right.$ quartiles). Statistical analysis was performed using Statistica 7.0 (StatSoft, Inc., OK, USA).

\section{Results and discussion}

The data obtained are shown in (Table I). The values were compared with the average reference values.

In the study patients, the following results were coagulation parameters: normal to moderately increased

\footnotetext{
*Address for correspondence: Alexander N. Osipenko, Central Educational and Research Laboratory, Mogilev State A. Kuleshov University, Mogilev, Surganova Street, 3/45, BY - 212026, Republic of Belarus, phone: +37 52913146 71, e-mail: alosipenko@yandex.by 
Table I. Haemostasis and von Willebrand factor (vWF) activity in study patients

\begin{tabular}{|c|c|c|c|c|c|}
\hline Parameter & $\begin{array}{l}\text { Reference range: } \\
\text { lower-upper limits }\end{array}$ & $\mathrm{n}$ & $\begin{array}{c}\text { Observations } \\
\text { Median }\left(25^{\text {th }}-75^{\text {th }} \text { quartiles }\right) \\
\min -\max \end{array}$ & $\begin{aligned} & \mathrm{n}[\%] \\
< & \text { lower limit }\end{aligned}$ & $\begin{aligned} & n[\%] \\
> & \text { upper limit }\end{aligned}$ \\
\hline PT ratio [s] & $11.9-16.1$ & 16 & $\begin{array}{c}15.7(14.7-16.5) \\
13.4-21.8\end{array}$ & $0(0)$ & $5(31.3)$ \\
\hline APTT ratio [s] & $24.6-35$ & 16 & $\begin{array}{c}35.2(30-44.25) \\
26.8-175\end{array}$ & $0(0)$ & $8(50)$ \\
\hline INR & $0.85-1.15$ & 16 & $\begin{array}{c}1.14(1.06-1.21) \\
0.95-1.68\end{array}$ & $0(0)$ & $6(37.5)$ \\
\hline PCA [\%] & $70-130$ & 16 & $\begin{array}{c}88.5(81.8-99.7) \\
50.6-119.0\end{array}$ & $1(6.3)$ & $0(0)$ \\
\hline Fibrinogen $[\mathrm{g} / \mathrm{L}]$ & $2.0-4.0$ & 16 & $\begin{array}{c}4.98(3.84-5.74) \\
3.13-7.41\end{array}$ & $0(0)$ & $12(75.0)$ \\
\hline Plasminogen [\%] & 81.4-141 & 12 & $\begin{array}{c}96.2(79.4-110.0) \\
53.4-132\end{array}$ & $3(25.0)$ & $0(0)$ \\
\hline Antithrombin III [\%] & $83-128$ & 16 & $\begin{array}{c}90.3(69.3-105.5) \\
59.1-132\end{array}$ & $6(37.5)$ & $2(12.5)$ \\
\hline D-dimer $[\mu \mathrm{g} / \mathrm{mL}]$ & $0-0.26$ & 13 & $\begin{array}{c}0.45(0.31-0.56) \\
0.26-3.38\end{array}$ & - & $12(92.3)$ \\
\hline vWF [\%] & $38-169$ & 16 & $\begin{array}{c}448(335-513) \\
223.2-889\end{array}$ & $0(0)$ & $16(100)$ \\
\hline
\end{tabular}

PT ratio - prothrombin time ratio; APTT ratio - activated partial thromboplastin ratio; INR - international normalized ratio; PCA - prothrombin complex activity

APTT values; normal prothrombin time values, normal INR values; normal prothrombin complex activity; normal plasminogen level; normal antithrombin III level; increased fibrinogen and D-dimer levels; significantly increased vWF activity.

Increase in D-dimer and fibrinogen levels in COVID-19 indicates the hypercoagulation among these patients. The vWF plays an essential role in primary haemostasis by ensuring platelet adhesion to the damaged vascular wall and their further aggregation as well as by binding to factor VIII and stabilising it [7, 8]. An increase in the activity of vWF to such extreme values indicates the important role of endothelial damage and its high involvement in the pathological process that occurs in the conditions of a systemic inflammatory response caused by $\mathrm{CO}$ VID-19 infection. In addition, an increase in the activity of VWF to extreme values is evidence of extreme instability of hemostasis with all its pathophysiological and clinical consequences.

Undoubtedly, this issue requires a more detailed study and careful analysis to ensure the correct interpretation of this parameter and further use of the vWF activity in clinical practice for diagnosis and treatment of COVID-19 patients. vWF activity may be used to develop new approaches to assess the severity of hemostasis disorders while COVID-19. It is also likely that the vWF may be a target for monoclonal antibody therapy or protease specific therapy.

\section{Conclusion}

Increased fibrinogen and D-dimer levels indicate that COVID-19 patients are in a state of hypercoagulation. In all patients, also a significant increase in vWF activity was observed. The increase in vWF activity reflects the of vascular endothelial damage in COVID-19 and may be one of the important causes of coagulation disorder in these patients.

\section{Authors' contributions}

All authors - contributed to writing and review of the manuscript.

\section{Conflict of interest}

The authors stated that they have no conflicts of interest regarding the publication of this article.

\section{Financial support}

This research received no external funding. 


\section{Ethics}

The work described in this article has been carried out in accordance with The Code of Ethics of the World Medical Association (Declaration of Helsinki) for experiments involving humans; EU Directive 2010/63/EU for animal experiments; Uniform Requirements for manuscripts submitted to Biomedical journals.

\section{References}

1. Escher R, Breakey N, Lämmle B. Severe CoVID-19 infection associated with endothelial activation. Thromb Res. 2020; 190: 62, doi: 10.1016/j.thromres.2020.04.014, indexed in Pubmed: 32305740.

2. Gupta A, Madhavan MV, Sehgal K, et al. Extrapulmonary manifestations of COVID-19. Nat Med. 2020; 26(7): 1017-1032, doi: 10.1038/s41591-020-0968-3, indexed in Pubmed: 32651579.

3. Panigada M, Bottino N, Tagliabue $P$, et al. Hypercoagulability of COVID-19 patients in intensive care unit: a report of throm- boelastography findings and other parameters of hemostasis. J Thromb Haemost. 2020; 18(7): 1738-1742, doi: 10.1111/ /jth.14850, indexed in Pubmed: 32302438.

4. Yousuf B, Alsarraf AH, Alfoudri H. Acute ischemic stroke - an extrapulmonary COVID-19 presentation. Crit Care Shock. 2020; 23(4): 196-200.

5. Xiao M, Zhang Y, Zhang S, et al. Coagulopathy and antiphospholipid antibodies in patients with COVID-19. N Engl J Med. 2020; 382(17): e38-2004, doi: 10.1056/NEJMc2007575, indexed in Pubmed: 32268022.

6. Carsana L, Sonzogni A, Nasr A, et al. Pulmonary post-mortem findings in a series of COVID-19 cases from northern Italy: a two-centre descriptive study. Lancet Infect Dis. 2020; 20(10): 1135-1140, doi: 10.1016/s1473-3099(20)30434-5.

7. Peyvandi F, Garagiola I, Baronciani L. Role of von Willebrand factor in the haemostasis. Blood Transfus. 2011; 9(Suppl 2): s3-s8, doi: 10.2450/2011.002S, indexed in Pubmed: 21839029.

8. Palta S, Saroa R, Palta A. Overview of the coagulation system. Indian J Anaesth. 2014; 58(5): 515-523, doi: 10.4103/0019-5049.144643, indexed in Pubmed: 25535411. 